\title{
Smart Generator Monitoring System in Industry Using Microcontroller
}

\author{
S. Boopathi ${ }^{1}$, M. Jagadeeshraja ${ }^{2}$, L. Manivannan ${ }^{2}$, M. Dhanasu ${ }^{3}$ \\ ${ }^{1}$ Embedded System Technologies, Knowledge Institute of Technology, Tamilnadu, India \\ ${ }^{2}$ Department of Electrical and Electronics Engineering, Knowledge Institute of Technology, Tamilnadu, India \\ ${ }^{3}$ Steel Authority of India, Tamilnadu, India
}

Email address:

booengineer@gmail.com (S. Boopathi)

\section{To cite this article:}

S. Boopathi, M. Jagadeeshraja, L. Manivannan, M. Dhanasu. Smart Generator Monitoring System in Industry Using Microcontroller. American Journal of Electrical Power and Energy Systems. Vol. 4, No. 4, 2015, pp. 45-50. doi: 10.11648/j.epes.20150404.13

\begin{abstract}
The electrical power systems are highly non-linear, extremely huge and complex networks. On the other hand, all the developed and countries have not sufficient supply of power. My Project focuses the detection of power failure and takes reflex action to solve the problem with help of GSM communication. The power failure will be detect by relay, and it communicates to Microcontroller to alerts the authorized person. In addition to that, parameters of Generator like Fuel level, Oil level, Temperature, battery status, etc., are monitored and communicated to authorized person. The acquired parameters are processed and recorded in the system memory. If there is any abnormality in their process, according to some predefined instruction and policies that are stored on the embedded system EEPROM then GSM alerts to concerned person immediately.
\end{abstract}

Keywords: Microcontroller, GSM Modem (SIM 300), Fuel Level (PH606), Oil Level (R Series), Temperature Sensors (LM35)

\section{Introduction}

The use of Generators has become a very common in almost every passive infrastructure companies, Industries, hospitals, Townships etc. while using these Generators a number of challenges are faced by the user such as maintaining the Quality of grid power, asset protections, generator maintenance, capturing real time data, Remotely monitoring of the generator, fuel theft monitoring, Data collection Analysis issues, Human dependency etc.

The Generator Monitoring System (GMS) is designed specifically for emergency power generators to monitor engine operations and detect pre-alarms or failures. This insures you of increased generator availability and a rapid response to service problems. The GMS monitors the power generators placed at the remote areas and increases its Efficiency by monitoring the various parameters of generator, Reporting critical Problems minimizes downtime and maximizes availability by sending generator failure messages instantly to you for diagnosis and emergency service dispatch if required.

It works on GSM technology, GMS can monitor various parameters such as external power supply, the battery voltage, fuel level, etc.

This system provides ideal solution to the problems caused in situations when a wired connection between a remote appliance/device and the control unit might not be feasible. The project is aimed to analyzing and testing the use of mobile phones to remotely monitor an appliance control system through GSM based wireless communication.

\section{Literature Survey}

Amit sachen et al have discussed the user can send commands in the form of SMS messages to read the remote electrical parameters. This system also can automatically send the real time electrical parameters periodically (based on time settings) in the form of SMS. This system can be designed to send SMS alerts whenever the Circuit Breaker trips or whenever the Voltage or Current exceeds the predefined limits. This project makes use of an onboard computer which is commonly termed as microcontroller [1].

Mallikarjun et al proposed this system is a specially designed computer system that is completely encapsulated by the device it controls. The embedded system has specific requirements and performs pre-defined tasks. The diesel generator is used when electricity is not readily available, or 
when power failures occur due to natural disasters such as typhoons or floods, or during other unexpected crises. Generally, the diesel generator operates in analog. The analog type controller cannot be processed precisely due to the distortions and noises coming from the data. In order to increase data accuracy, the controller needs to be digitalized [2]

Vimalraj et al have described a distribution transformers have a long service life if they are operated under good and rated conditions. However, their life is significantly reduced if they are overloaded, resulting in unexpected failures and loss of supply to a large number of customers thus effecting system reliability. This system provides flexible control of load parameters accurately and also provides effective means for rectification of faults if any abnormality occurs in power lines using SMS through GSM network [3].

Andriy Palamar et al proposed the system the Cellular phone containing SIM (Subscriber's Identifying Module) card has a specific number through which communication takes place. The mode of communication is wireless and mechanism works on the GSM (Global System for Mobile communication) technology. Here, the communication is made bi- directional where the user transmits and also receives instructions to and from the system in the form of SMS [4].

Kwang Seon Ahn et al have discussed the Using remote management; you can check operating hours, oil pressure, battery status, coolant temperatures, generated power output, fuel level, GPS position and more. A notification also could be generated whenever a critical level has been reached, such as when a generator has been running more than expected, or when the running hours exceed the service interval [5].

Henrik Arleving proposed system by using a cloud-based remote management solution with a communication gateway can help reduce costs, avoid fuel theft and improve power

generator control. It can be difficult to focus on the right actions, simply because there isn't enough information on fuel levels, oil pressure or battery status for each generator. With a cloud-based remote management solution, we can have immediate access to generator parameters via a regular web browser being able to analyse each generator remotely enables you to better understand their health and more efficiently schedule field service visits and Fuel theft can be a significant problem[6].

Chetan Patil et al have discussed the design of BTS safety and fault management system the measures are taken to rectify these problems. The method makes use of GSM modem which gives the instant message about the each activity happening in the site. The temperature sensors will sense the temperature of the room and if it rises above the threshold value the GSM module will send the message to the master mobile which is already set in the system [7].

Y Jaganmohan Reddy et al is discussed the model of combination of Photo Voltaic (PV) cell System, Wind turbine system, Fuel cell (FC), and Battery systems for power generation, and to improve power quality they proposing Motor-Generator model instead of using static converters, and an energy management and control unit using Programmable Logic Controller (PLC). The power transformer is regarded as the heart of any electrical transmission and distribution system [8].

A.P.Agalgaonkar et al have discussed the measurement and control of temperature, humidity and the other parameters at different places. The Data Acquisition is defined as the process of taking a real-world signal as input, such as a voltage or current any electrical input, into the computer, for processing, analysis, storage or other data manipulation or conditioning[9].

\section{Block Diagram}

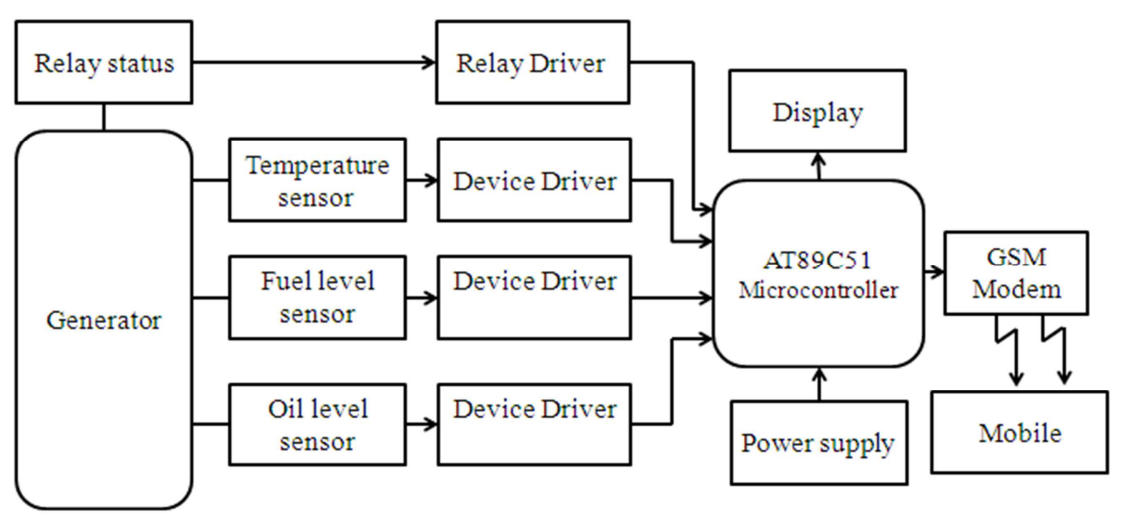

Fig. 1. Block Diagram of Proposed System.

\section{Description of Proposed Method}

The system has two parts, namely; hardware and software. The hardware architecture consists of a stand-alone embedded system that is based on Microcontroller a GSM handset with GSM Modem and a driver circuit. The GSM modem provides the communication by means of SMS messages. The SMS message consists of commands to be executed. The SMS message is sent to the GSM modem via the GSM public networks as a text message with a definite predefined format. Once the GSM modem receives negative signal from the EB supply, it sends the SMS to the user consisting of non-availability of power supply, fuel level, temperature of the coolant, etc. 
The user can decide whether to switch the generator on/off and issue the command. Based on the message, the commands sent will be extracted and executed by the Microcontroller. In this case, if the EB power supply resumes, again the user is made to know the status of on-site..

\subsection{Microcontroller}

The AT89S51 is a low-power, high-performance CMOS 8- bit microcontroller with $8 \mathrm{~K}$ bytes of in-system programmable Flash memory. The device is manufactured using Atmel's high-density nonvolatile memory technology and is compatible with the industry standard 80C51 instruction set and pin out. The on-chip Flash allows the program memory to be reprogrammed in-system or by a conventional nonvolatile memory programmer.

\subsection{Sensor Used}

Tab 1. Description of Sensor types

\begin{tabular}{|c|c|c|}
\hline Sensor Types & Range & Description \\
\hline 1.Oil Level(R SERIES) & Detecting Range:10-2000mm & $\begin{array}{l}\text { The oil mainly used in generator for purpose of using cooling of generator. When } \\
\text { temperature of generator goes high, oil level in generator tank decreases due to } \\
\text { heating effect. }\end{array}$ \\
\hline 2.Temperature(LM35D) & Detecting Range: $-55^{\circ}$ to $+150^{\circ} \mathrm{C}$ & $\begin{array}{l}\text { The temperature sensor which is used to monitoring the generator temperature and } \\
\text { when the generator temperature exceeds predefined limits it is known through } \\
\text { temperature sensor. }\end{array}$ \\
\hline 3 .Fuel level(PH606) & Detecting Range : $10-2000 \mathrm{~mm}$ & $\begin{array}{l}\text { The fuel level sensor using to monitoring the fuel level of generator. The generator } \\
\text { to maintain the level of fuel and an abnormal decrease in content could indicate fuel } \\
\text { is being stolen. }\end{array}$ \\
\hline
\end{tabular}

\subsection{Relay}

Relay is an electrically operated switch. Many relays use an electromagnet to mechanically operate a switch, but other operating principles are also used, such as solid-state relays. Relays are used where it is necessary to control a circuit by a low-power signal (with complete electrical isolation between control and controlled circuits), or where several circuits must be controlled by one signal. The first relays were used in long distance telegraph circuits as amplifiers; they repeated the signal coming in from one circuit.

\subsection{GSM Modem (SIM 300)}

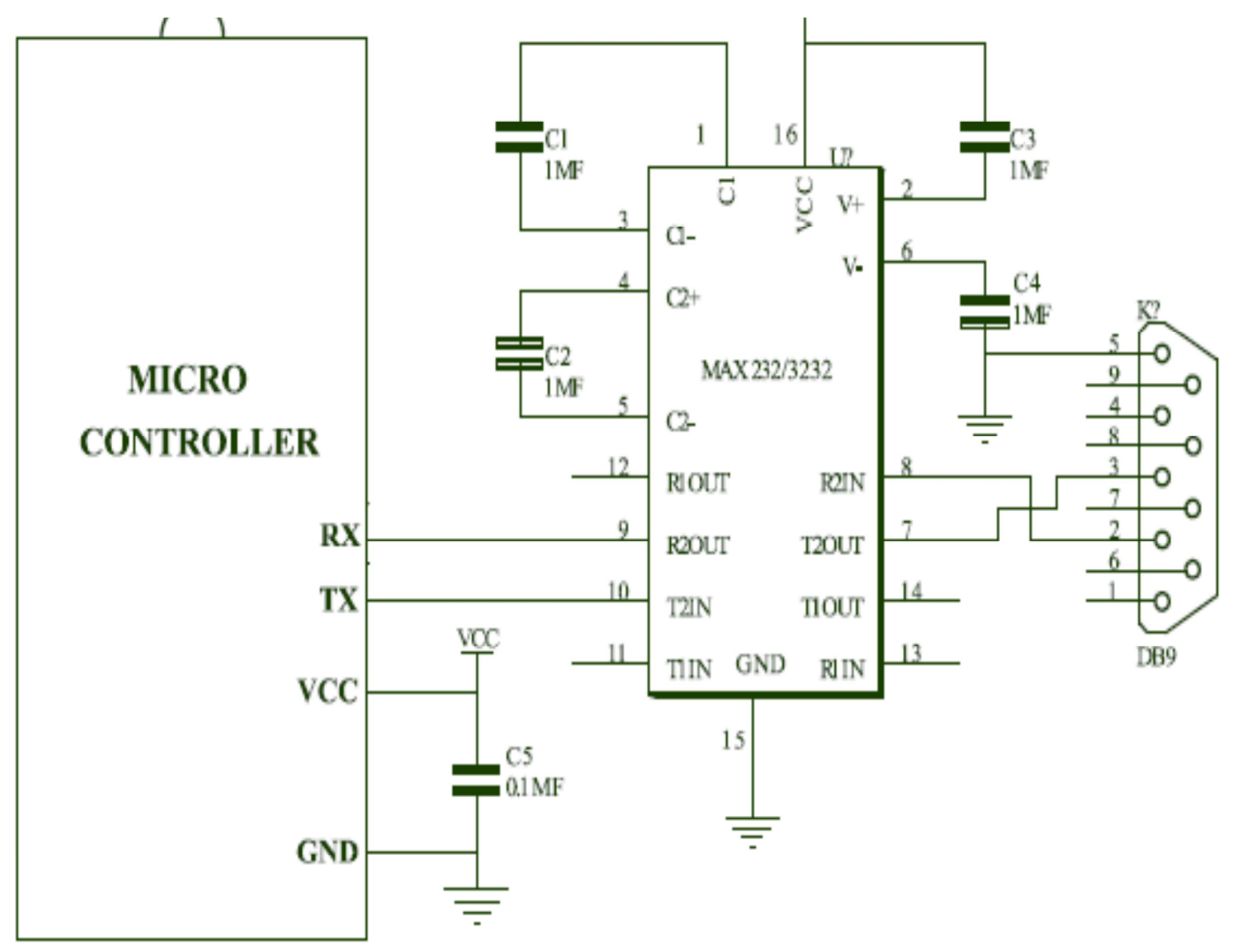

Fig 2. Connect MCU\&MAX232 communicate with GSM Modem. 
This GSM Modem can accept any GSM network operator SIM card and act just like a mobile phone with its own unique phone number. Advantage of using this modem will be that you can use its RS232 port to communicate and develop embedded applications. Applications like SMS Control, data transfer, remote control and logging can be developed easily. The modem can either be connected to PC serial port directly or to any microcontroller. It can be used to send and receive SMS or make/receive voice calls.
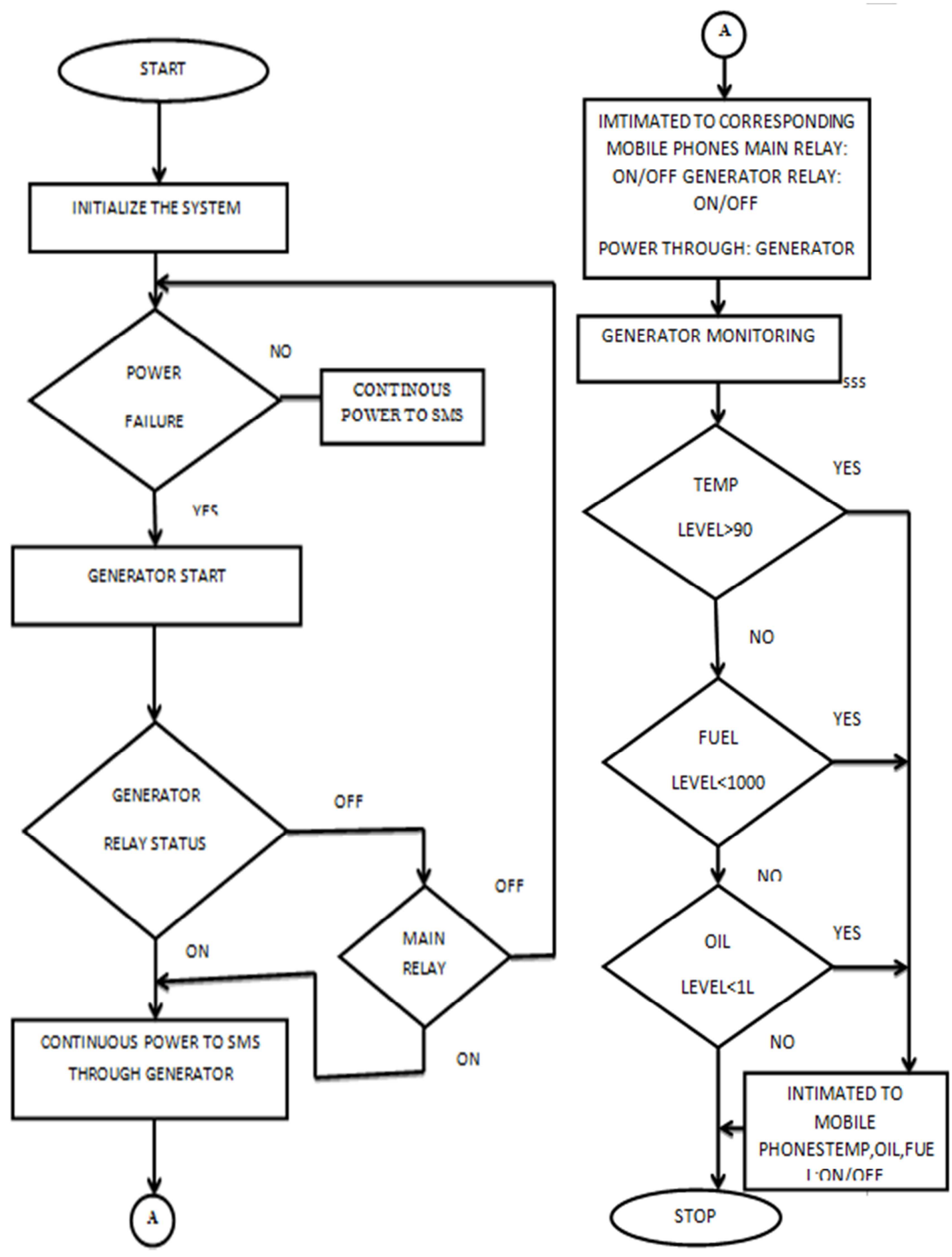

It can also be used in GPRS mode to connect to internet and do many applications for data logging and control.

The SIM300 is a complete Tri-band GSM solution in a compact plug-in module. Featuring an industry-standard interface, the SIM300 delivers GSM/GPR S900/1800/1900Mhz performance for voice, SMS, data and Fax in a small form factor and with low power consumption.

\subsection{Flow Chart}

Fig. 3. Flow Chart. 


\subsection{Algorithm}

Step 1: Start the program

Step 2: To initialize the system

Step 3: Get Hardware Software for relevant application.

Step 4: To monitoring the generator status and EB power and if any abnormal conditions occur it is automatically intimated to authorized person.

Step 5: If new SMS received on mobile and go to step3 else, go to step 1

Step 6: Receive SMS

Step 7: Check SMS pattern

Step 8: Control the device based on status and operator can making a decision.

Step 9: Notify end user

Step 10: Go to step1

\section{Output}

To monitor temperature range and fuel, oil level and circuit breaker status of generator.

Under normal condition

Temperature Range: 100 degree Celsius

Fuel Level: 1000 Liter

Oil Level: 4 Liter

Taking the data of previous fault condition and intimated automatically when they exist their limit. Regarding taking threshold value, we have to take account the normal fuel, temperature, oil of generator and associated errors.

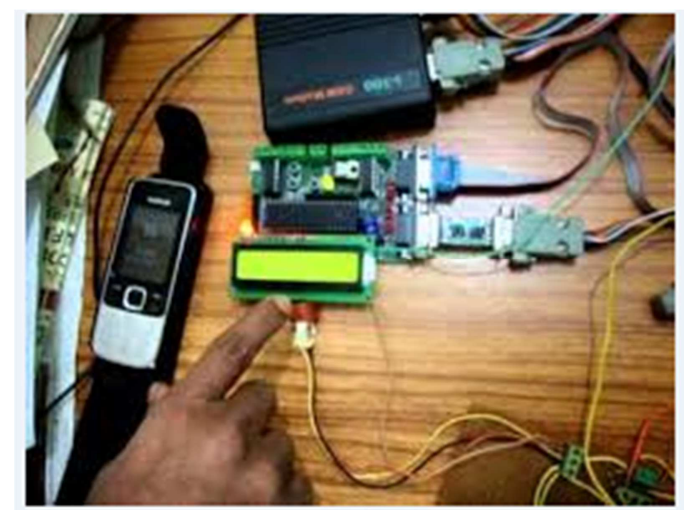

Fig. 4. Electronic Control Unit arrangement.

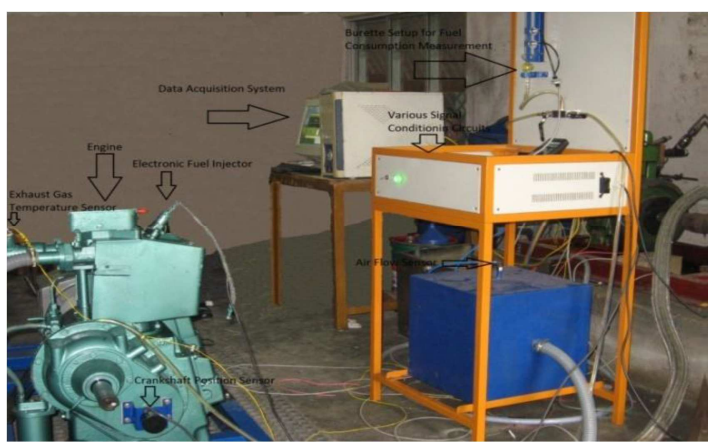

Fig. 5. Various sensor connections.

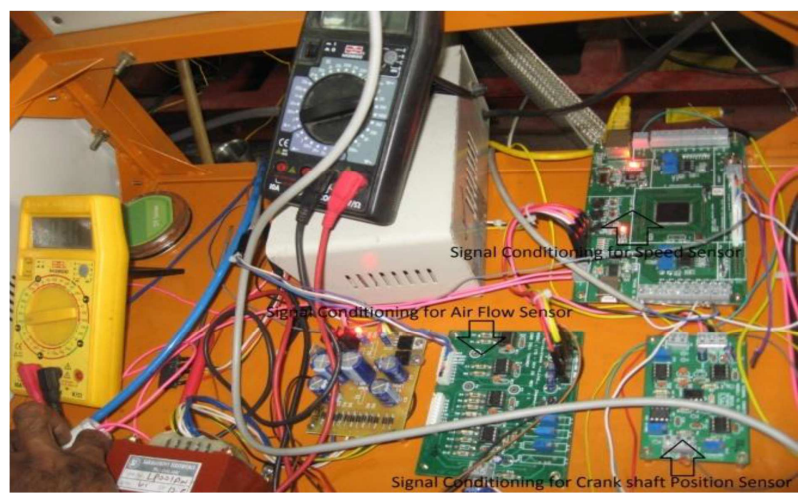

Fig. 6. Experimental Setup.

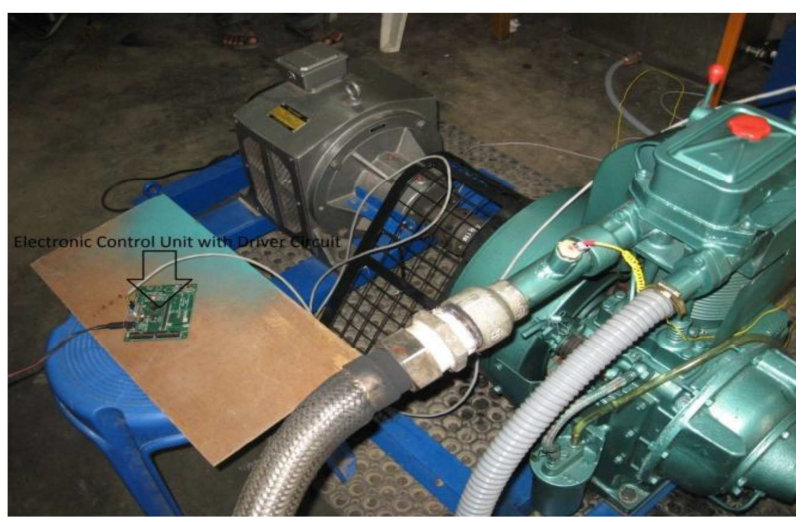

Fig. 7. Various Signal Conditioning Boards.

\section{Conclusion}

The hunch delineated of this project is immense in the ever changing technological world. It allows a greater degree of freedom to an individual to sway via GSM. In particular the suggested system will be a powerful, flexible and secure tool that will offer this service at any time, and from anywhere with the constraints of the technologies being applied. The embedded controllers are capable of sensing and controlling the various parameter of generator in normal and abnormal condition .this proposed system provides the immediate solution for catastrophic failure of generator using GSM communication. The embedded controller offers a wide scope of application in the field of remote digital controllers in the diesel generator industry.

\section{References}

[1] Amit Sachan, "Microcontroller based Based Substation Monitoring and Control System with Gsm Modem" IOSR Journal of Electrical and Electronics Engineering, ISSN: 2278-1676 Volume 1, Issue 6 (July-Aug. 2012).

[2] Mallikarjun Sarsamba "The Load Monitoring and Protection on Electricity Power lines using GSM Network" International Journal of Advanced Research in Computer Science and Software Engineering, Volume 3, Issue 9, September 2013 ISSN: 2277 128X. 
[3] S.Vimalraj, Gausalya.R.B, "GSM Based Controlled Switching Circuit between Supply Mains and Captive Power Plant" International Journal of Computational Engineering Research, Vol, 03, Issue, 4.April 2013.

[4] Andriy Palamar "Control System for a Diesel Generator and UPS Based Microgrid", Scientific Journal of Riga Technical University Power and Electrical Engineering, Volume 27, 2010.

[5] Kwang Seon Ahn "Digital Controller of a Diesel Generator using an Embedded System" International Journal of Information Processing Systems, Vol.2, No.3, December 2006.

[6] Henrik arleving "ways to cut power generator maintanence"the journal, December 2013.

[7] Chetan Patil, Channabasappa Baligar, "Base Transceiver Station (BTS) Safety and Fault Management", International

\section{Biography}

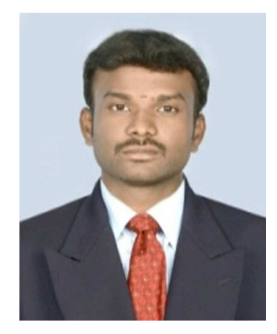

S. Boopathi is pursuing, $\mathrm{PG}$ in the discipline of Embedded System Technologies at Knowledge Institute of Technology, Salem, under Anna University, Chennai, India. He received him UG degree in the discipline of Electrical and electronics engineering in CMS collage of Engineering at Namakkal under Anna University, Coimbatore, India .He has published and presented a number of technical papers in Technical symposiums and he got best project award in project event international level organized by central government. $\mathrm{He}$ is an Executive member of Embedded Club in Knowledge Institute of Technology at Salem.

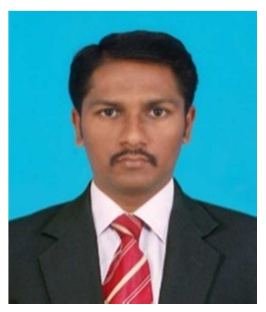

Mr. M. Jagadeeshraja is currently working as an Assistant Professor in the Department of Electrical and Electronics Engineering at Knowledge Institute of Technology, Salem. $\mathrm{He}$ received his B.E. - Electrical and Electronics Engineering Degree from Paavai Engineering College under Anna University, Chennai and M.E. - Embedded System Technologies form Academic Campus, Anna University of Technology, Coimbatore. $\mathrm{He}$ has published and presented number of technical papers in National and International conferences. He is guiding number of projects for UG and PG students.
Journal of Innovative Technology and Exploring Engineering (IJITEE) ISSN: 2278-3075, Volume-3, Issue-7, December 2013.

[8] Y Jaganmohan Reddy, Y V Pavan Kumar, K Padma Raju, Anilkumar Ramsesh, "PLC Based Energy Management and Control Design for an Alternative Energy Power System with Improved Power Quality", International Journal of Engineering Research and Applications (IJERA) ISSN: 22489622 Vol. 3, Issue 3, May-Jun 2013.

[9] Alper T. Alan "A Field Study of Human-Agent Interaction for Electricity Tariff Switching", Agents, Interaction and Complexity Group, University of Southampton, Southampton, UK.

[10] J. Pierce and E. Paulos. Beyond energy monitors: interaction, energy, and emerging energy systems. In Proc. CHI'12. ACM, 2012 .

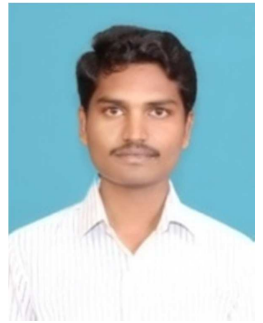

Mr. L. Manivannan is currently working as an Assistant Professor in the Department of Electrical and Electronics Engineering at Knowledge Institute of Technology, Salem, Tamilnadu. He received his UG degree in the discipline of Electrical and Electronics Engineering from Institute of Road and Transport Technology under Anna University, Chennai and PG degree in the discipline of Power Electronics and Drives from K.S.R. College of Engineering under Anna University of Technology, Coimbatore. He presented technical papers at National and International level conferences.

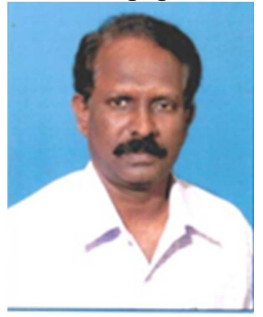

Mr. M. Dhanasu is currently working as an Assistant General Manager in the Department of Electrical at, Salem Steel Plant. He received his B.E. - Electrical and Electronics Engineering Degree from Government Engineering College under Anna University, Chennai and M.E. Applied Electronics Government engineering College, under Anna University of Technology, Salem. His research includes in Embedded System, Re-winding of distribution transformer, industrial Drives and control, PLC, SCADA for power system. He has published and presented number of technical papers in National and International conferences. 